\title{
The landscape of knowledge translation interventions in cancer control: What do we know and where to next? A review of systematic reviews
}

Melissa C Brouwers ${ }^{1,2^{*}}$, Kimberly Garcia ${ }^{1}$, Julie Makarski ${ }^{1}$ and Lubna Daraz ${ }^{3}$ and for of the Evidence Expert Panel, for of the KT for Cancer Control in Canada Project Research Team

\begin{abstract}
Background: Effective implementation strategies are needed to optimize advancements in the fields of cancer diagnosis, treatment, survivorship, and end-of-life care. We conducted a review of systematic reviews to better understand the evidentiary base of implementation strategies in cancer control.

Methods: Using three databases, we conducted a search and identified English-language systematic reviews published between 2005 and 2010 that targeted consumer, professional, organizational, regulatory, or financial interventions, tested exclusively or partially in a cancer context (primary focus); generic or non-cancer-specific reviews were also considered. Data were extracted, appraised, and analyzed by members of the research team, and research ideas to advance the field were proposed.

Results: Thirty-four systematic reviews providing 41 summaries of evidence on 19 unique interventions comprised the evidence base. AMSTAR quality ratings ranged between 2 and 10. Team members rated most of the interventions as promising and in need of further research, and 64 research ideas were identified.

Conclusions: While many interventions show promise of effectiveness in the cancer-control context, few reviews were able to conclude definitively in favor of or against a specific intervention. We discuss the complexity of implementation research and offer suggestions to advance the science in this area.
\end{abstract}

\section{Background}

Innovations in screening and early detection, development of effective treatment interventions, and strategies to improve quality of life have emerged from primary studies, and systematic reviews of these studies, in cancer control [1-9]. These advancements have the capacity to reduce mortality and morbidity from disease. However, optimizing these advancements requires their appropriate application, a goal that is often difficult to achieve $[10,11]$. Understanding what are the most effective and promising interventions is warranted to ensure that the appropriate options are chosen and incorporated into implementation plans and prioritized for

\footnotetext{
* Correspondence: mbrouwer@mcmaster.ca

${ }^{1}$ McMaster University, Department of Oncology, Hamilton, Ontario, Canada Full list of author information is available at the end of the article
}

future research studies. The analysis of studies examining the effectiveness of implementation interventions is a key component to an overall knowledge translation (KT) research agenda [12].

The purpose of our study was to conduct a review of systematic reviews to better understand the evidentiary foundation regarding what is known about KT interventions. Specifically, we wanted to better understand the strengths and limitations of the field, to identify what interventions are ready for use now, and to identify research priorities and directions for the future. We were interested in studies conducted in the context of cancer control across the care continuum, from diagnoses to survivorship and end-of-life care, and across cancer diagnoses. We chose this scope given that "context" has been identified as an important consideration

\section{C) Biomed Central}


in the design and execution of implementation strategies and is a concept central to several $\mathrm{KT}$ models and research paradigms [12-15].

\section{Methods}

Overview

This project, Knowledge Translation to Improve Cancer Control in Canada, was funded by the Ontario Institute for Cancer Research and the Canadian Partnership Against Cancer. It received ethics approval from the Hamilton Health Sciences/Faculty of Health Sciences Research Ethics Board, McMaster University, Hamilton, Ontario, Canada. The design, execution, analysis, and reporting of the project was editorially independent from the funders.

To avoid duplication of effort, and to complete the study in the required time, we capitalized on available high-quality databases profiling systematic reviews of interventions to systematically search for, appraise, and evaluate the effectiveness of $\mathrm{KT}$ interventions that met our inclusion criteria. Aligning with existing categorical schemes (Canadian Agency for Drugs and Technologies in Health [CADTH] and Cochrane Collaboration's Effective Practice and Organisation of Care [EPOC] group), we sought interventions that targeted the groupings of consumers/patients/public (i.e., consumer interventions), clinicians and healthcare providers (i.e., professional interventions), organizational/managers/system leaders (i.e., organizational interventions), regulatory (i.e., new health service delivery regulation), and financial (i.e., incentives).

\section{Search}

To identify existing systematic reviews that met our inclusion criteria, we used three databases as our sources:

1. Rx for Change (CADTH-EPOC Group Collaborative Initiative): http://www.cadth.ca/en/resources/rx-forchange/database

2. Health Systems Evidence (formerly, Program in Policy Decision-Making), McMaster University: http://www. healthsystemsevidence.org/

3. McMaster KT+, McMaster University: http://plus. mcmaster.ca/kt/Default.aspx

\section{Eligibility criteria \\ Inclusion criteria}

- Study designs: Systematic reviews published between 2005 and 2010. While the methodology is still evolving, this interval was chosen to align with best evidence suggesting median survival time of a systematic review is approximately five years [16].

- Outcomes: Systematic reviews that included at least one of the following outcomes: measurable clinical outcomes, observable behavior change, documented intention to behave, documented attitudes, documented knowledge uptake, or reported stakeholder satisfaction.

- KT interventions: Interventions that focused on at least one of the following target groupings: consumer, professional, organization, regulatory, and financial, as outlined in the CADTH-EPOC framework.

- Clinical scenarios:

O Diagnosis: Interventions that were tested in cancer-specific environments (any cancer diagnosis). Reviews that included cancer as part of the clinical context or that were generic/nonspecific to clinical condition were also considered.

- Stage of continuum of care: Diagnosis, treatment, follow-up, survivorship, end-of-life $[17]^{\mathrm{a}}$.

\section{Exclusion criteria}

- Study designs: Any design other than systematic reviews.

- Language: Non-English language due to cost and availability of translations.

\section{Data extraction}

Data were extracted from the systematic reviews meeting our eligibility criteria. For all reviews, data extracted included (i) intervention name/label; (ii) intervention definition and purpose; (iii) theories, frameworks, or models used to inform the design or execution of the intervention; (iv) key operational elements underpinning the execution of the intervention; (v) setting; (vi) geography (where the intervention was tested); (vii) stakeholder involvement (who and type of involvement); (viii) evaluation strategy; (ix) measurement instrument(s); (x) quality indicators and outcomes; (xi) recommendations and conclusions; (xii) cost information and/or information regarding sustainability of the intervention; and (xiii) AMSTAR quality appraisal (if available).

\section{Quality control and critical appraisal}

Title, abstract, and full-text screenings were done in duplicate (KG and LD). Disagreements were resolved by consensus or by a third party (JM). Data extraction and critical appraisal (if required) were conducted by one researcher and audited by a second. In circumstances where appraisal was not completed by the original source, the systematic reviews were appraised using AMSTAR [18], an 11-item evaluation tool assessing methodological standards, presentation, and critical appraisal in systematic reviews. AMSTAR ratings can range between 1 and 11 , with 11 denoting highest quality. 


\section{Interpretation of systematic reviews' results and research priorities/direction}

Data tables describing the systematic review study characteristics and results were circulated to subgroups of the research team (see Additional File 1). For each assigned systematic review and using a 7-point scale, members of the subgroups were asked to indicate their "assessment of effectiveness" for each intervention reviewed based on their interpretation of the data. A rubric was designed to guide these assessments and the interpretation of the rating scale. Interventions rated between 1 and 3 were considered ineffective, interventions rated 4 and 5 were considered promising and worth additional investigation, and interventions rated 6 or 7 were considered effective. Average scores of ratings were calculated for each systematic review. Investigators were then asked to identify any specific research priorities or research questions they thought relevant.

\section{Results \\ Overall}

The initial search for systematic reviews yielded 591 reviews for consideration from the three source databases. Of these, a total of 38 reviews were originally considered and 31 retained $[19]^{\mathrm{b}}$. An additional three reviews were included post hoc, identified by members of the research team (see Additional File 2).

In total, 34 unique systematic review publications providing 41 evidence summaries on 19 unique interventions comprised the evidence base. Table 1 provides the definitions of the interventions considered. Some systematic reviews addressed more than one intervention or provided more than one evidence summary; in addition, more than one systematic review was available for some of the interventions. Additional File 2 provides the references for the included systematic reviews.

The overall quality of the systematic reviews, as measured by the AMSTAR tool [18], was moderate. The systematic reviews were most apt to target the treatment stage of the continuum and least likely to target survivorship (Table 2). Further, despite being a highly prevalent disease site, few systematic reviews targeted patients with lung cancer (Table 3). Some less prevalent diagnoses (head and neck, sarcoma, and melanoma) were rarely or never targeted. A significant number of reviews did not specify cancer diagnosis.

With respect to characteristics of the systematic reviews (Table 4), most did not specify whether a KT theory, model or framework was used to inform the design of the project or the intervention itself. Most of the reviews used a mixture of study designs as their primary evidentiary source, and only four reviews used non-randomized controlled trial (RCT) data exclusively as their primary evidence. Most systematic review authors reported poorly executed and poorly reported primary studies.

Common outcomes reported in the literature were measures of knowledge, satisfaction, and observed behavior and, to a lesser extent, clinical outcomes. Indeed, 7 of 17 consumer evidence summaries reported clinical outcomes, while 12 reported on knowledge, 10 reported on behavior observed, 9 reported on satisfaction, 8 reported on behavior intention, and 6 reported on attitude. For professional evidence summaries, 11 of 14 reported clinical outcomes, compared to knowledge (2), satisfaction (2), and behavior observed (10). Similarly, the most reported outcome for organizational evidence summaries were clinical outcomes (8), compared to behavior observed (7), satisfaction (7), knowledge (4), attitude (2), and behavior intention (1). However, when considering across the 41 evidence summaries in our sample, only 15 of 41 reported clinical outcomes.

With respect to intervention context (Table 5), clinicians were most often delivering the intervention, and a clinical environment (e.g., clinics, hospitals) was the most common setting for the intervention to take place. Interventions were most often delivered in person, by paper, or by phone. Technology-based modalities were used less often unless they defined the intervention itself (e.g., electronic medical record, clinical decision support systems).

The following sections, including the tables and additional files, provide an overview of the results by cluster of main intervention groupings. For more information on the complete raw data set, readers are asked to contact the corresponding author.

\section{Interventions aimed at consumers (Additional File 3)}

Sixteen publications addressing six unique consumer interventions provided 17 evidence summaries. Consumer interventions included education/information provision, decision-making aids, and interventions to support behavior change. Tables 4, 5, and 6 summarize characteristics of the systematic reviews; Table 7 summarizes the quality and efficacy appraisals of the interventions; and Table 8 summarizes the research suggestions made by members of the team.

The overall quality of the systematic reviews targeting consumer interventions was variable, ranging from poor to high. The average AMSTAR score was 7, with scores ranging from 3 to 10 . Most of the systematic reviews did not include a meta-analysis or an empirical synthesis of findings. Evidence of effectiveness was most promising for patient education (e.g., improvements in patient knowledge and clinical outcomes); decision aids (e.g., improvements in patient knowledge and satisfaction, reduction in patient decisional conflict, and impact on decisions); and interactive health communication 
Table 1 Intervention definitions

\begin{tabular}{|c|c|}
\hline Intervention & Definition \\
\hline \multicolumn{2}{|r|}{ Consumer interventions } \\
\hline Education & $\begin{array}{l}\text { interventions informing patients about their treatment and their health (education, information } \\
\text { provision, promotion of health) }\end{array}$ \\
\hline $\begin{array}{l}\text { Decision aids/shared decision-making } \\
\text { interventions }\end{array}$ & $\begin{array}{l}\text { interventions designed to assist patients make specific and deliberative choices among options by } \\
\text { providing information on the options and outcomes relevant to a person's health status }\end{array}$ \\
\hline $\begin{array}{l}\text { Interactive health communication } \\
\text { application (IHCA) interventions }\end{array}$ & $\begin{array}{l}\text { interventions aimed at enabling interactions between an individual and a communication technology } \\
\text { to access or transmit health information, to receive guidance, or to receive support }\end{array}$ \\
\hline Contracts & $\begin{array}{l}\text { a behavioral strategy aimed at improving patient adherence by setting out a set of rules regarding } \\
\text { the behavior of interest and formalizing commitment to adhere to the rules }\end{array}$ \\
\hline Reminder packaging & $\begin{array}{l}\text { interventions aimed to facilitate safe and appropriate medication use (e.g., monitored dose symptoms, } \\
\text { multi-compartment aids) }\end{array}$ \\
\hline Multifaceted interventions & $\begin{array}{l}\text { two or more interventions aimed at assisting patients with adherence to treatment/medications and } \\
\text { improving the prescription process }\end{array}$ \\
\hline \multicolumn{2}{|r|}{ Professional interventions } \\
\hline $\begin{array}{l}\text { Educational outreach and audit and } \\
\text { feedback }\end{array}$ & $\begin{array}{l}\text { interventions whereby a trained person meets with providers in their practice setting to give } \\
\text { information with the goal to change clinical behavior (also referred to as academic detailing) OR any } \\
\text { summary of clinical performance (from health records, observation, computer systems) of healthcare } \\
\text { over a specified time that may also include recommendations for clinical action }\end{array}$ \\
\hline $\begin{array}{l}\text { Clinical decision support systems (IT/IM/ } \\
\text { informatics) }\end{array}$ & $\begin{array}{l}\text { information system interventions that provide the clinician with decision support, including critical } \\
\text { clinical data, reminders, advice on drug or care provision, etc. }\end{array}$ \\
\hline $\begin{array}{c}\text { Computerized physician order entry (IT/IM/ } \\
\text { informatics) }\end{array}$ & $\begin{array}{l}\text { computer-based systems for ordering medications with automated aspects to the ordering process, } \\
\text { such as a list of possible medications for a physician to choose, drug interaction or contraindication } \\
\text { prompts, reminders, etc. }\end{array}$ \\
\hline Tracker/reminder systems (IT/IM/informatics) & $\begin{array}{c}\text { specific interventions that prompt healthcare providers with information specific to the patient or the } \\
\text { encounter that would advise on action to do or action to avoid (interventions can be verbal, paper, } \\
\text { or electronic) }\end{array}$ \\
\hline Local opinion leaders & educational leaders and influentials nominated by their colleagues \\
\hline Tailored interventions & identify barriers to change and subsequent design of an intervention that addresses identified barriers \\
\hline Clinical pathways & $\begin{array}{l}\text { document-based tools that provide a link between best available evidence and clinical practice by } \\
\text { providing recommendations, processes, and time-frames for the management of specific medical } \\
\text { conditions or interventions }\end{array}$ \\
\hline Guidelines for professions allied to medicine & $\begin{array}{l}\text { a systematic statement aimed at assisting in decisions by providers and patients for a specific clinical } \\
\text { condition }\end{array}$ \\
\hline Discharge planning from hospital to home & interventions aimed at providing individualized plans as a patient is moved from hospital to home \\
\hline \multicolumn{2}{|r|}{ Organizational interventions } \\
\hline Changing length of consultation & interventions designed to increase consult time between primary care provider and patient \\
\hline Routine standard assessment interventions & $\begin{array}{l}\text { interventions designed to improve the assessment and documentation of patients (akin to pathology } \\
\text { checklist concept in Ontario or surgical checklist concept in various provinces) }\end{array}$ \\
\hline Chronic care model interventions & $\begin{array}{l}\text { interventions aimed at redesigning ambulatory care by modifying elements of the chronic care } \\
\text { model (elements include self-management support, decision support, delivery system design, clinical } \\
\text { information systems, healthcare organizations, and community resources) }\end{array}$ \\
\hline Shared-care interventions & $\begin{array}{l}\text { any type of structured system that involves continuing collaborative clinical care between primary } \\
\text { care and specialty care in the management of patients }\end{array}$ \\
\hline Shared-care tactic interventions & $\begin{array}{c}\text { tactics aimed to facilitate information sharing between providers who provide care to a patient; } \\
\text { include (i) liaison meetings-meetings between specialists and primary care teams whereby ongoing } \\
\text { management of patients within the service is planned and discussed, (ii) shared-care record cards-a } \\
\text { formal information-sharing arrangement where a set of data is agreed to, entered onto a record card, } \\
\text { and usually carried by the patient, or (iii) computer-assisted shared care/email-a formal information- } \\
\text { sharing arrangement whereby a data set is agreed to, entered onto a record card, and shared } \\
\text { between two sectors on computer (can also include coordinated computer registration and patient } \\
\text { recall) }\end{array}$ \\
\hline Health information technology interventions & switching the format or structure of the medical record, such as computerized medical records \\
\hline
\end{tabular}


Table 2 Systematic reviews: Stage in continuum of cancer care and implementation intervention cluster

\begin{tabular}{lcccccccc}
\hline Cluster & \multicolumn{7}{c}{ Continuum-of-care stage } \\
\hline & Prevention & Screening & Diagnosis & Treatment & Survivorship & Follow-up & Supportive care & Palliative end-of-life care \\
\hline Professional & 5 & 7 & 7 & 10 & 1 & 2 & 2 & 2 \\
\hline Consumer & 4 & 2 & 8 & 16 & 1 & 3 & 8 & 4 \\
\hline Organizational & 1 & 3 & 6 & 8 & 1 & 3 & 4 & 0 \\
\hline Financial & 0 & 0 & 0 & 0 & 0 & 0 & 0 & 0 \\
\hline Regulatory & 0 & 0 & 0 & 0 & 0 & 0 & 0 & 0 \\
\hline
\end{tabular}

applications (e.g., improvements in knowledge, social support, behavior, and clinical outcomes). Most reviews within a given intervention type yielded significant variability with respect to effectiveness, and most authors were unable to provide definitive conclusions to their use.

Assessments by research team members on effectiveness yielded overall mean scores (across evidence summaries of similar interventions) ranging between 3.8 and 6.0 (see "Team Ratings" column of Table 7). Only one, interactive health communication applications, was rated as being effective. The remaining interventions were rated as promising and candidates for more study. Eight research ideas and three systematic review topics were identified by members of the research team (Table 8).

\section{Interventions aimed at professionals (Additional File 4)}

Twelve publications addressing seven unique professional interventions provided 14 evidence summaries. Professional interventions included education, audit and feedback, information technology (IT)/information management (IM)/informatics, clinical decision support systems, computerized physician order entry, reminders, local opinion leaders, tailored interventions, clinical pathways, guidelines, and discharge planning. Tables 4 , 5 , and 9 summarize characteristics of the systematic reviews; Table 10 summarizes the quality and efficacy appraisals for the interventions; and Table 11 summarizes the research suggestions made by members of the research team.

For these systematic reviews, the average AMSTAR score was 6 , with scores ranging from 3 to 8 . Trials that comprised the reviews included RCTs, clinical controlled trials, pre-/post studies, cluster RCTs, time series, observational, and trials labeled as "other." Of the 14 evidence summaries, 4 undertook quantitative pooling (i.e., meta-analysis).

Evidence of effectiveness was most promising for educational outreach and audit and feedback interventions (median improvement in clinical outcomes 5\%); clinical decision support (improved clinical performance); computer order entry (reduction in medical errors); clinical pathways (reduction in complication rates); local opinion leaders (reduction in clinician noncompliance); and tailored interventions (improvement in some clinical outcomes). However, these benefits are contrasted against the concerns with the overall quality and lack of consistency across the systematic reviews. Moreover, the primary studies included in the systematic reviews are reported to be of poor quality, heterogeneous, and poorly reported with respect to the interventions, contexts, and measurements of outcomes. Together, this makes definitive conclusions about professional interventions very challenging.

Table 3 Systematic reviews: Cancer diagnosis and implementation intervention cluster

\begin{tabular}{|c|c|c|c|c|c|c|}
\hline & & \multicolumn{5}{|c|}{ Cluster } \\
\hline & & Professional & Consumer & Organizational & Financial & Regulatory \\
\hline \multirow{11}{*}{ Diagnosis } & Breast & 4 & 9 & 4 & 0 & 0 \\
\hline & Gastrointestinal & 2 & 2 & 2 & 0 & 0 \\
\hline & Genitourinary & 2 & 4 & 2 & 0 & 0 \\
\hline & Gynecological & 1 & 1 & 1 & 0 & 0 \\
\hline & Head and neck & 0 & 2 & 0 & 0 & 0 \\
\hline & Hematologic & 1 & 2 & 1 & 0 & 0 \\
\hline & Lung & 0 & 3 & 0 & 0 & 0 \\
\hline & Melanoma & 1 & 1 & 1 & 0 & 0 \\
\hline & Neuro-oncology & 0 & 0 & 0 & 0 & 0 \\
\hline & Sarcoma & 1 & 0 & 1 & 0 & 0 \\
\hline & Not specified & 5 & 6 & 5 & 0 & 0 \\
\hline
\end{tabular}


Table 4 Characteristics of systematic reviews

\begin{tabular}{|c|c|c|c|c|c|c|c|c|c|c|c|c|}
\hline \multirow[t]{2}{*}{ Type of intervention (number of evidence summaries) } & \multicolumn{3}{|c|}{ Theory/framework } & \multicolumn{3}{|c|}{ Study designs included } & \multicolumn{6}{|c|}{ Outcomes included } \\
\hline & $\mathrm{Y}$ & $\mathrm{N}$ & NS & RCT only & Non-RCT only & Mixed & C & BO & $\mathrm{BI}$ & K & A & $\mathrm{S}$ \\
\hline \multicolumn{13}{|c|}{ Consumer interventions } \\
\hline Patient education/patient information $(n=8)$ & 2 & 0 & 6 & 2 & 0 & 6 & 4 & 3 & 6 & 6 & 4 & 5 \\
\hline Decision aids/shared decision making $(n=5)$ & 2 & 2 & 1 & 0 & 0 & 5 & 1 & 3 & 2 & 4 & 1 & 3 \\
\hline Interactive health communication applications $(n=1)$ & 0 & 0 & 1 & 1 & 0 & 0 & 1 & 1 & 0 & 1 & 0 & 0 \\
\hline Contracts $(n=1)$ & 1 & 0 & 0 & 1 & 0 & 0 & 0 & 1 & 0 & 1 & 0 & 1 \\
\hline Reminder packaging $(\mathrm{n}=1)$ & 0 & 0 & 1 & 1 & 0 & 0 & 0 & 1 & 0 & 0 & 1 & 0 \\
\hline Multifaceted $(n=1)$ & 0 & 0 & 1 & 1 & 0 & 0 & 1 & 1 & 0 & 0 & 0 & 0 \\
\hline Overall & 5 & 2 & 10 & 6 & 0 & 11 & 7 & 10 & 8 & 12 & 6 & 9 \\
\hline \multicolumn{13}{|c|}{ Professional interventions } \\
\hline Educational outreach visits \& audit and feedback $(n=4)$ & 1 & 2 & 1 & 2 & 1 & 1 & 4 & 2 & 0 & 2 & 0 & 1 \\
\hline IT/IM/informatic interventions $(n=5)$ & 0 & 1 & 4 & 0 & 1 & 4 & 4 & 5 & 0 & 0 & 0 & 0 \\
\hline Local opinion leaders $(n=1)$ & 0 & 0 & 1 & 1 & 0 & 0 & 0 & 1 & 0 & 0 & 0 & 0 \\
\hline Tailored interventions $(\mathrm{n}=1)$ & 1 & 0 & 0 & 1 & 0 & 0 & 1 & 0 & 0 & 0 & 0 & 0 \\
\hline Clinical pathway interventions $(n=1)$ & - & - & - & 0 & 0 & 1 & 1 & 1 & 0 & 0 & 0 & 0 \\
\hline Guidelines for professions allied to medicine $(n=1)$ & - & - & - & 0 & 0 & 1 & 0 & 1 & 0 & 0 & 0 & 0 \\
\hline Discharge planning from hospital to home $(n=1)$ & - & - & - & 1 & 0 & 0 & 1 & 0 & 0 & 0 & 0 & 1 \\
\hline Overall & 2 & 3 & 6 & 5 & 2 & 7 & 11 & 10 & 0 & 2 & 0 & 2 \\
\hline \multicolumn{13}{|c|}{ Organizational interventions } \\
\hline Changing length of consultation $(n=1)$ & 0 & 0 & 1 & 0 & 0 & 1 & 1 & 1 & 0 & 0 & 0 & 1 \\
\hline Routine standardized assessment $(n=1)$ & 0 & 0 & 1 & 0 & 0 & 1 & 1 & 1 & 0 & 1 & 1 & 1 \\
\hline Chronic care model interventions $(n=1)$ & 1 & 0 & 0 & 0 & 0 & 1 & 0 & 1 & 0 & 0 & 0 & 0 \\
\hline Models-of-care/integrated care-related interventions $(n=5)$ & 0 & 2 & 3 & 0 & 2 & 3 & 4 & 2 & 1 & 3 & 1 & 3 \\
\hline Shared-care tactic interventions $(n=1)$ & 0 & 1 & 0 & 0 & 0 & 1 & 1 & 1 & 0 & 0 & 0 & 1 \\
\hline Health information technology $(n=1)$ & 1 & 0 & 0 & 0 & 0 & 1 & 1 & 1 & 0 & 0 & 0 & 1 \\
\hline Overall & 2 & 3 & 5 & 0 & 2 & 8 & 8 & 7 & 1 & 4 & 2 & 7 \\
\hline
\end{tabular}

$\mathrm{Y}=$ yes; $\mathrm{N}=$ no; $\mathrm{NS}=$ not specified; $\mathrm{RCT}=$ randomized controlled trial; $\mathrm{C}=$ clinical; $\mathrm{BO}=$ behaviour observed; $\mathrm{BI}=$ behaviour intention; $\mathrm{K}=\mathrm{knowledge} ; \mathrm{A}=$ attitudes; $\mathrm{S}=$ satisfaction; IT = information technology; IM = information management.

Note: The reviews added post-hoc (Rotter, 2010; Shepperd, 2010; Thomas, 2009) did not have full data extraction completed; this is indicated by cells with "-".

Research team ratings of the interventions were assessed, and the overall mean scores (across evidence summaries of the same intervention) ranged between 4.3 and 5.0 all were within the "promising" category (see "Team Ratings" column in Table 10). Twenty-eight research ideas were recommended by members of the research team (see Table 11).

\section{Interventions aimed at organizations (Additional File 5)}

Nine reports addressing six unique organizational interventions provided 10 evidence summaries. The interventions included organizational/structural specific, continuity-of-care related, shared-care tactics, revisions of professional roles, and health information technology. Tables 4, 5, and 12 summarize characteristics of the systematic reviews; Table 13 summarizes the quality and efficacy appraisals of the interventions; and Table 14 summarizes the research suggestions made by members of the team.

Organizational interventions are those aimed at encouraging use and uptake of knowledge at the organizational level. The average AMSTAR score was 5, with scores ranging from 2 to 8 , which indicates the range of very poor methodological quality to moderately high methodological quality. Overall, the reviews were not able to provide definite conclusions (e.g., statistically significant findings) to support the use of any of the specific interventions reviewed.

Two of the interventions, changing length of consultation time and shared-care tactic interventions, were rated by members of the research team as not effective (ratings of 3 and under). The remaining interventions fell between 4 and 5 on the scale, indicating promise and are candidates for further study (see Table 13). 
Table 5 Characteristics of interventions studied Type of intervention (number of evidence summaries)

\section{Context: Who delivered Context: Where Context: How delivered \\ delivered}

Pt Fam Clin Ad PH O Home Comm CIE O Per Paper Phone TI TS NS Consumer interventions

\begin{tabular}{|c|c|c|c|c|c|c|c|c|c|c|c|c|c|c|c|c|}
\hline Patient education/patient information $(n=8)$ & 0 & 0 & 5 & 0 & 0 & 3 & 4 & 3 & 7 & 4 & 4 & 7 & 4 & 2 & 2 & 0 \\
\hline Decision aids/shared decision making $(n=5)$ & 0 & 0 & 5 & 0 & 0 & 0 & 2 & 0 & 3 & 2 & 2 & 5 & 1 & 4 & 2 & 0 \\
\hline Interactive health communication applications ( $\mathrm{n}=1$ ) & 0 & 0 & 0 & 0 & 0 & 1 & 1 & 1 & 1 & 0 & 1 & 1 & 0 & 1 & 1 & 0 \\
\hline Contracts $(n=1)$ & 0 & 0 & 1 & 0 & 0 & 0 & 1 & 0 & 1 & 0 & 1 & 1 & 0 & 0 & 0 & 0 \\
\hline Reminder packaging $(n=1)$ & 1 & 1 & 1 & 0 & 0 & 1 & 1 & 1 & 1 & 1 & 1 & 0 & 0 & 0 & 1 & 0 \\
\hline Multifaceted $(n=1)$ & 1 & 1 & 1 & 0 & 0 & 1 & 1 & 1 & 1 & 1 & 1 & 1 & 1 & 1 & 1 & 0 \\
\hline Overall & 2 & 2 & 13 & 0 & 0 & 6 & 10 & 6 & 14 & 8 & 10 & 15 & 6 & 8 & 7 & 0 \\
\hline \multicolumn{17}{|c|}{ Professional interventions } \\
\hline Educational outreach visits \& audit and feedback $(n=4)$ & 0 & 0 & 3 & 1 & 0 & 2 & 0 & 1 & 4 & 1 & 4 & 4 & 3 & 2 & 1 & 0 \\
\hline IT/IM/informatic interventions $(n=5)$ & 0 & 0 & 2 & 1 & 0 & 4 & 0 & 2 & 5 & 1 & 0 & 0 & 0 & 4 & 1 & 0 \\
\hline Local opinion leaders $(n=1)$ & 0 & 0 & 1 & 0 & 0 & 0 & 0 & 0 & 1 & 0 & 1 & 0 & 0 & 0 & 0 & 0 \\
\hline Tailored interventions $(\mathrm{n}=1)$ & 0 & 0 & 0 & 0 & 0 & 1 & 0 & 1 & 1 & 0 & 0 & 0 & 0 & 0 & 0 & 1 \\
\hline Clinical pathway interventions $(n=1)$ & 0 & 0 & 1 & 0 & 0 & 0 & - & - & - & - & - & - & - & - & - & - \\
\hline Guidelines for professions allied to medicine $(n=1)$ & 0 & 0 & 1 & 0 & 0 & 0 & - & - & - & - & - & - & - & - & - & - \\
\hline Discharge planning from hospital to home $(n=1)$ & 0 & 0 & 1 & 0 & 0 & 0 & - & - & - & - & - & - & - & - & - & - \\
\hline Overall & 0 & 0 & 9 & 2 & 0 & 7 & 0 & 4 & 11 & 2 & 5 & 4 & 3 & 6 & 2 & 1 \\
\hline \multicolumn{17}{|c|}{ Organizational interventions } \\
\hline Changing length of consultation $(n=1)$ & 0 & 0 & 1 & 0 & 0 & 0 & 0 & 0 & 1 & 0 & 1 & 0 & 0 & 0 & 0 & 0 \\
\hline Routine standardized assessment $(n=1)$ & 0 & 0 & 1 & 0 & 0 & 1 & 0 & 0 & 1 & 0 & 1 & 1 & 0 & 0 & 0 & 0 \\
\hline Chronic care model interventions $(n=1)$ & 0 & 0 & 1 & 0 & 0 & 1 & 0 & 1 & 1 & 0 & 1 & 0 & 0 & 0 & 0 & 1 \\
\hline $\begin{array}{l}\text { Models-of-care/integrated care-related interventions ( } \mathrm{n}= \\
5 \text { ) }\end{array}$ & 0 & 0 & 5 & 0 & 0 & 0 & 1 & 2 & 5 & 1 & 5 & 4 & 2 & 2 & 0 & 0 \\
\hline Shared-care tactic interventions $(\mathrm{n}=1)$ & 0 & 0 & 1 & 0 & 0 & 0 & 1 & 1 & 1 & 1 & 1 & 1 & 1 & 1 & 0 & 0 \\
\hline Health information technology $(n=1)$ & 0 & 0 & 1 & 1 & 0 & 0 & 0 & 0 & 1 & 0 & 0 & 0 & 0 & 1 & 0 & 0 \\
\hline Overall & 0 & 0 & 10 & 1 & 0 & 2 & 2 & 4 & 10 & 2 & 9 & 6 & 3 & 4 & 0 & 1 \\
\hline
\end{tabular}

$\mathrm{Pt}=$ patients; Fam = family; Clin = clinicians; $\mathrm{Ad}=$ administrator $/$ manager; $\mathrm{PH}=$ public health; $\mathrm{O}=$ other; Comm = community; $\mathrm{ClE}=\mathrm{clinical}$ environment; Per = person; $\mathrm{TI}=$ technology-interactive; TS = technology-static; NS = not specified; IT = information technology; IM = information management.

Note: The reviews added post-hoc (Rotter, 2010; Shepperd, 2010; Thomas, 2009) did not have full data extraction completed; this is indicated by cells with "-".

Table 6 Consumer-focused interventions: Number of systematic reviews for each cluster

\begin{tabular}{ccccc}
\hline Type of intervention & $\begin{array}{c}\text { Total number of } \\
\text { SRs }\end{array}$ & $\begin{array}{c}\text { Number of SRs-cancer } \\
\text { only }\end{array}$ & $\begin{array}{c}\text { Number of SRs- } \\
\text { mixed }\end{array}$ & $\begin{array}{c}\text { Number of SRs- no } \\
\text { cancer }\end{array}$ \\
\hline Patient education and patient information & 8 & 4 & 4 & 0 \\
\hline Patient decision aids & 5 & 3 & 2 & 0 \\
\hline $\begin{array}{c}\text { Interactive health communication } \\
\text { applications }\end{array}$ & 1 & 0 & 1 & 0 \\
\hline Contracts & 1 & 0 & 0 & 1 \\
\hline Reminder packaging & 1 & 0 & 0 & 1 \\
\hline Multifaceted & 1 & 0 & 1 & 0 \\
\hline
\end{tabular}

$\mathrm{SR}=$ systematic review. 
Table 7 Consumer interventions: Appraisal of systematic review (AMSTAR) scores and intervention effectiveness ratings by research team

\begin{tabular}{|c|c|c|c|}
\hline \multirow[t]{3}{*}{ Intervention cluster and systematic review first author (year) } & \multicolumn{3}{|c|}{ Scores and ratings } \\
\hline & \multirow[t]{2}{*}{ AMSTAR (1 to 11$)$} & \multicolumn{2}{|c|}{ Research team ratings } \\
\hline & & Mean & SD \\
\hline \multicolumn{4}{|l|}{ Patient education/patient information } \\
\hline Bennett (2009) [26] & 8 & 5.7 & 0.67 \\
\hline Gaston (2005a) [35] & 5 & 4.7 & 0.45 \\
\hline Gysels (2007) [37] & 5 & 3.0 & 1.00 \\
\hline Goldberg (2007a) [36] & 3 & 3.8 & 0.45 \\
\hline Wofford (2005) [56] & 7 & 4.3 & 0.84 \\
\hline Santo (2005) [47] & 7 & 4.6 & 0.89 \\
\hline Conn (2008) [30] & 10 & 4.3 & 1.79 \\
\hline Raynor (2007) [45] & 8 & 4.0 & 0.71 \\
\hline Overall mean score & 7 & & \\
\hline \multicolumn{4}{|l|}{ Patient decision aids } \\
\hline Evans (2005) [33] & 7 & 4.4 & 1.14 \\
\hline Gaston (2005b) [35] & 5 & 4.3 & 0.97 \\
\hline Waljee (2007) [54] & 8 & 6.1 & 0.22 \\
\hline Edwards (2008) [32] & 5 & 3.8 & 0.45 \\
\hline Joosten (2008) [41] & 5 & 5.1 & 0.22 \\
\hline Overall mean score & 6 & & \\
\hline \multicolumn{4}{|l|}{ Interactive health communication applications } \\
\hline Murray (2005) [43] & 11 & 6 & 1 \\
\hline \multicolumn{4}{|l|}{ Contracts } \\
\hline Bosch-Capblanch (2007) [27] & 9 & 3.8 & 0.84 \\
\hline \multicolumn{4}{|l|}{ Reminder packaging } \\
\hline Heneghan (2006) [39] & 10 & 5.1 & 0.74 \\
\hline \multicolumn{4}{|l|}{ Multifaceted } \\
\hline Haynes (2008) [38] & 10 & 4.6 & 0.89 \\
\hline
\end{tabular}

Table 8 Consumer interventions: Nominated research ideas

\begin{tabular}{|c|c|}
\hline Type of intervention & Research ideas \\
\hline Patient education/patient information & $\begin{array}{l}\text { Randomized studies directly comparing different intervention formats/modalities/techniques on satisfaction, } \\
\text { adherence, and clinical outcomes (prioritize those interventions from which individual studies have shown } \\
\text { greatest promise on clinical outcomes) (i.e., how to do it) }\end{array}$ \\
\hline \multirow[t]{2}{*}{ Decision aids } & $\begin{array}{c}\text { Development, testing, and evaluation of cancer decision aids in understudied areas (e.g., role within } \\
\text { personalized medicine, molecular-genetics) }\end{array}$ \\
\hline & Development, testing, and evaluation of cancer decision aids in understudied populations \\
\hline $\begin{array}{l}\text { Interactive health communication } \\
\text { applications (IHCA) }\end{array}$ & What are the implications for IHCA on privacy policies and legislations? \\
\hline Contract interventions & Outside of cancer prevention, no role \\
\hline \multirow[t]{2}{*}{ Reminder packaging } & $\begin{array}{r}\text { Research to identify if adherence to medication protocols is a problem for cancer patients (e.g., for which } \\
\text { drugs, cancer diagnoses, complexity of drug regimen) }\end{array}$ \\
\hline & $\begin{array}{c}\text { Generalize to other aspects of cancer care-What are effective strategies to remind cancer survivors of } \\
\text { follow-up and monitoring regimens? (linked to discharge plan priorities) }\end{array}$ \\
\hline Multifaceted intervention & $\begin{array}{c}\text { Design and evaluate multifaceted consumer interventions for specific cancer control problems using Haynes } \\
\text { et al. review as foundation (i.e., deconstruct systematic review to identify most promising intervention } \\
\text { clusters for specific contexts) }\end{array}$ \\
\hline Systematic review priorities & $\begin{array}{c}\text { Acquiring skills and competencies } \\
\text { Consumer system participation } \\
\text { Minimizing risks or harms }\end{array}$ \\
\hline
\end{tabular}


Table 9 Professional-focused interventions: Number of systematic reviews for each cluster

\begin{tabular}{ccccc}
\hline $\begin{array}{c}\text { Type of intervention } \\
\text { Educational outreach visits \& audit and } \\
\text { feedback }\end{array}$ & $\begin{array}{c}\text { Total number of } \\
\text { SRs }\end{array}$ & $\begin{array}{c}\text { Number of SRs-cancer } \\
\text { only }\end{array}$ & $\begin{array}{c}\text { Number of SRs- } \\
\text { mixed }\end{array}$ & $\begin{array}{c}\text { Number of SRs- no } \\
\text { cancer }\end{array}$ \\
\hline IT/IM/informatics & 5 & 2 & 2 \\
\hline Local opinion leaders & 1 & 1 & 4 & 0 \\
\hline Tailored interventions & 1 & 0 & 0 & 0 \\
\hline Clinical pathways & 1 & 0 & 1 & 1 \\
\hline $\begin{array}{c}\text { Guidelines for professions allied to } \\
\text { medicine }\end{array}$ & 1 & 0 & 1 & 0 \\
\hline Discharge planning from hospital to home & 1 & 0 & 1 \\
\hline
\end{tabular}

SR = systematic review; $I T$ = information technology; IM = information management.

Twenty-eight research ideas were recommended by members of the research team (see Table 14).

\section{Conclusion}

We considered 34 unique systematic reviews providing 41 evidence summaries for $19 \mathrm{KT}$ interventions. The quality of the execution of the systematic reviews varied significantly, with AMSTAR ratings ranging between 2 and 10. Primary evidence serving as the foundation for the systematic reviews included RCTs and nonrandomized trials. Systematic review authors describe the primary evidence as uneven with respect to quality, reporting, and outcomes.

While many interventions suggested promise of effectiveness, few reviews were able to conclude definitively

Table 10 Professional interventions: Appraisal of systematic review (AMSTAR) scores and intervention effectiveness ratings by research team

\begin{tabular}{|c|c|c|c|}
\hline \multirow[t]{3}{*}{ Intervention cluster and systematic review first author (year) } & \multicolumn{3}{|c|}{ Scores and ratings } \\
\hline & \multirow[t]{2}{*}{ AMSTAR (1 to 11$)$} & \multicolumn{2}{|c|}{ Research team ratings } \\
\hline & & Mean & SD \\
\hline \multicolumn{4}{|l|}{ Educational outreach visit $\&$ audit and feedback interventions } \\
\hline Goldberg (2007b) [36] & 3 & 4.6 & 0.89 \\
\hline O'Brien (2007) [44] & 8 & 4.8 & 1.17 \\
\hline Goldberg (2007c) [36] & 3 & 3.8 & 0.98 \\
\hline Jamtvedt (2006) [40] & 8 & 4.7 & 0.82 \\
\hline Overall mean score & 5.5 & \multicolumn{2}{|c|}{4.5} \\
\hline \multicolumn{4}{|l|}{ IT/IM/informatic interventions } \\
\hline Goldberg (2007d) [36] & 3 & 3.7 & 0.52 \\
\hline Garg (2005) [34] & 5 & 5.3 & 0.52 \\
\hline Ammenwerth (2008) [23] & 6 & 5.7 & 0.52 \\
\hline Beach (2006a) [25] & 5 & 5.7 & 1.03 \\
\hline Shojania (2009) [50] & 8 & 4.7 & 0.52 \\
\hline Overall mean score & 5.4 & \multicolumn{2}{|c|}{5.0} \\
\hline \multicolumn{4}{|l|}{ Local opinion leader interventions } \\
\hline Doumit (2007) [31] & 7 & 4.3 & 0.82 \\
\hline \multicolumn{4}{|l|}{ Tailored interventions } \\
\hline Baker (2010) [24] & 7 & 4.8 & 1.47 \\
\hline \multicolumn{4}{|l|}{ Clinical pathway interventions } \\
\hline Rotter $(2010)^{a}[46]$ & - & NA & NA \\
\hline \multicolumn{4}{|l|}{ Guidelines for professions allied to medicine } \\
\hline Thomas $(2009)^{a}[53]$ & - & NA & NA \\
\hline \multicolumn{4}{|l|}{ Discharge planning from hospital to home } \\
\hline Shepperd $(2010)^{a}[49]$ & - & NA & NA \\
\hline
\end{tabular}

${ }^{a}$ These reviews were included post hoc, identified by members of the research team.

IT = information technology; IM = information management. 
Table 11 Professional interventions: Nominated research ideas

\begin{tabular}{|c|c|}
\hline Type of intervention & Research ideas \\
\hline \multirow[t]{5}{*}{$\begin{array}{l}\text { Educational outreach visits (EOV)/audit } \\
\text { and feedback (AF) }\end{array}$} & $\begin{array}{l}\text { Better quality trials directly evaluating specific modalities and methods of EOV (proper randomization, } \\
\text { baseline data, variety of outcomes-including patient outcomes and costing) }\end{array}$ \\
\hline & Better quality trials directly evaluating specific modalities and methods of methods of AF (as above) \\
\hline & For which clinicians, clinical conditions, and stage in the continuum is EOV most impactful? \\
\hline & For which clinicians, clinical conditions, and stage in the continuum is AF most impactful? \\
\hline & What is the impact of regional AF versus individual AF on changing patterns of practice? \\
\hline \multirow[t]{5}{*}{ IT/IM/informatic interventions } & $\begin{array}{l}\text { Better quality trials directly evaluating specific modalities and methods of informatic interventions (proper } \\
\text { randomization }\end{array}$ \\
\hline & $\begin{array}{l}\text { For which clinicians, clinical conditions, and stage in the continuum are informatics interventions most } \\
\text { impactful? }\end{array}$ \\
\hline & Develop methods to enable practice guidelines to be directly integrated into informatic interventions \\
\hline & What is the cost effectiveness of different informatic interventions? \\
\hline & Are informatic interventions effective in non-drug-prescribing aspects of cancer care? \\
\hline \multirow[t]{3}{*}{ Local opinion leader interventions } & Methodological development in choosing local opinion leaders in a reliable manner \\
\hline & $\begin{array}{l}\text { Methodological development in understanding factors that increase and decrease sustainability of local } \\
\text { opinion leader designation }\end{array}$ \\
\hline & $\begin{array}{l}\text { Research to better understand for which provider groups and under what clinical contexts (cancer } \\
\text { diagnosis, practice setting, stage of the cancer trajectory) local opinion leaders are most effective }\end{array}$ \\
\hline \multirow[t]{4}{*}{ Tailored interventions } & Methodological analysis of the operational techniques of tailoring in existing high-quality primary studies \\
\hline & Methodological development to determine when tailoring has or has not addressed identified barriers \\
\hline & Identification of defining factors of effective tailoring \\
\hline & $\begin{array}{l}\text { Direct comparisons of different tailoring interventions (tactic and modality, etc.) on uptake of evidence, } \\
\text { processes of care, and clinical outcomes }\end{array}$ \\
\hline \multirow[t]{5}{*}{ Clinical pathway interventions } & Testing of clinical pathway interventions on different stages of continuum of cancer care \\
\hline & Testing of clinical pathway interventions with different healthcare providers involved in cancer control \\
\hline & $\begin{array}{l}\text { Methodological development to determine for which clinical problem (e.g., cancer diagnosis, complexity } \\
\text { of care) clinical pathways are most effective }\end{array}$ \\
\hline & $\begin{array}{l}\text { Direct comparisons of different clinical pathway strategies (methods and modality, etc.) on uptake of } \\
\text { evidence, processes of care, and clinical outcomes }\end{array}$ \\
\hline & Is the introduction of clinical pathways cost effective in Ontario/Canada? \\
\hline \multirow[t]{4}{*}{ Guidelines } & $\begin{array}{l}\text { Compare and contrast use of and impact of guidelines on processes of care and clinical outcome as a } \\
\text { function of cancer care provider }\end{array}$ \\
\hline & Testing innovative strategies to disseminate guideline messages to different providers \\
\hline & Testing of innovative strategies to disseminate guideline messages to administrators \\
\hline & Testing of innovate strategies to disseminate guideline messages to policy makers \\
\hline \multirow[t]{2}{*}{ Discharge planning } & $\begin{array}{l}\text { What are the defining features/components to a discharge plan that are linked to patient satisfaction, } \\
\text { provider satisfaction, process outcomes, and clinical outcomes? }\end{array}$ \\
\hline & Determining the specific clinical components for discharge plans for different cancer diagnoses \\
\hline
\end{tabular}

IT = information technology; IM = information management.

Table 12 Organizational-focused interventions: Number of systematic reviews for each cluster

\begin{tabular}{ccccc}
\hline Type of intervention & $\begin{array}{c}\text { Total number of } \\
\text { SRs }\end{array}$ & $\begin{array}{c}\text { Number of SRs-cancer } \\
\text { only }\end{array}$ & $\begin{array}{c}\text { Number of SRs- cancer } \\
\text { included }\end{array}$ & $\begin{array}{c}\text { Number of SRs- no } \\
\text { cancer }\end{array}$ \\
\hline $\begin{array}{c}\text { Changing length of } \\
\text { consultation }\end{array}$ & 1 & 0 & 0 & 1 \\
\hline Routine standard assessment & 1 & 1 & 0 & 0 \\
\hline Chronic care model & 1 & 0 & 3 & 0 \\
\hline $\begin{array}{c}\text { Models of care/integrated } \\
\text { care }\end{array}$ & 5 & 2 & 1 & 0 \\
\hline $\begin{array}{c}\text { Shared-care tactic } \\
\text { Health information } \\
\text { technology }\end{array}$ & 1 & 0 & 1 & 0 \\
\hline
\end{tabular}

$\mathrm{SR}=$ systematic review. 
Table 13 Organizational-focused interventions: Appraisal of systematic review (AMSTAR) scores and intervention effectiveness ratings by research team

\begin{tabular}{|c|c|c|c|}
\hline \multirow[t]{3}{*}{ Intervention cluster and relevant systematic review first author (year) } & \multicolumn{3}{|c|}{ Scores and ratings } \\
\hline & \multirow[t]{2}{*}{ AMSTAR (1 to 11 ) } & \multicolumn{2}{|c|}{ Research team ratings } \\
\hline & & Mean & SD \\
\hline \multicolumn{4}{|l|}{ Changing length of consultation interventions } \\
\hline Wilson (2006) [55] & 7 & 3 & 0.71 \\
\hline \multicolumn{4}{|l|}{ Routine standard assessment interventions } \\
\hline Goldberg (2007e) [36] & 3 & 3.8 & 1.30 \\
\hline \multicolumn{4}{|l|}{ Chronic care model interventions } \\
\hline Coleman (2009) [29] & 2 & 4.4 & 0.55 \\
\hline \multicolumn{4}{|l|}{ Models-of-care/integrated care-related interventions } \\
\hline Lewis (2009) [42] & 7 & 3.8 & 1.10 \\
\hline Smith (2008) [52] & 8 & 3.2 & 1.30 \\
\hline Beach (2006b) [25] & 5 & 4.6 & 0.89 \\
\hline Goldberg (2007f) [36] & 3 & 3.6 & 0.89 \\
\hline Scheuner (2008) [48] & 4 & 2.6 & 0.55 \\
\hline Overall mean score & 5.4 & & \\
\hline \multicolumn{4}{|l|}{ Shared-care tactic interventions } \\
\hline Smith (2007) [51] & 8 & 3 & 1.22 \\
\hline \multicolumn{4}{|l|}{ Health information technology interventions } \\
\hline Chaudhry (2006) [28] & 4 & 4.6 & 0.89 \\
\hline
\end{tabular}

in favor of or against a specific intervention. The interpretation of the evidence by members of the research team aligned with this analysis. The majority of the interventions were rated by the research team members as promising, but in need of additional study.

In considering $\mathrm{KT}$ in cancer control, one is struck by the complexity of the enterprise. While there are many studies being conducted, the quality is decidedly uneven and the impact on patient care or system performance is questionable. To that end, some key observations are noted and conclusions for the research enterprise can be drawn.

Overall, the approach to $\mathrm{KT}$ in cancer control appears patchy and unsystematic. While this may be due, in part, to the breadth, size, and scope of the research area, it is likely to be a major contributor to the hodgepodge of studies being conducted, the failure of the research community to consistently embrace high-quality research paradigms and standards, and the inability to create a common language and taxonomy in the field. Indeed, common across the systematic reviews considered here is that the studies that underpin them often fail to adequately describe all aspects of the KT intervention under investigation and (where relevant) the control group. This makes it very difficult to synthesize data, to improve the overall research enterprise, and to build from one study to another. Here, work by Cochrane's EPOC group and researchers such as Michie and others may assist in designing a common language, a common set of operational definitions, and common labels to facilitate the advancement of the KT field [20-22].

The complexity of the cancer field and the impact of that complexity to the KT research agenda cannot be underestimated. The numerous but unique diagnoses, the variety of providers involved in cancer care and control (i.e., public health, primary care, medical specialists, allied health providers, lay and peer providers), the various organizational settings in which care is offered, the risks associated with some care options, and the variability in decision-making styles by individuals affected by cancer are examples of this complexity. As it relates to the $\mathrm{KT}$ research enterprise, the role of context and individual differences must be stressed.

The design and execution of the primary studies fall below acceptable levels of quality. For example, we found that the systematic reviews often fail to measure meaningful end points because these data are not available in the primary literature that comprise the evidentiary base for synthesis. While measures of knowledge, satisfaction, and intention are important-and in fact, better studied-measures of intervention fidelity (or adherence to intervention), relevant clinical end points, and valid patient-centered outcomes are often lacking.

In addition, the design and execution of the systematic reviews in the KT field are uneven. For example, use of factorial designs, multilevel modeling techniques, and regression strategies could improve the precision by 
Table 14 Organizational interventions: Nominated research ideas

\begin{tabular}{|c|c|}
\hline Type of intervention & Research ideas \\
\hline \multirow[t]{4}{*}{ Changing length of consultation } & $\begin{array}{l}\text { Does length of consultation influence patient satisfaction, clinician satisfaction, or patient outcomes in a } \\
\text { clinical context? }\end{array}$ \\
\hline & $\begin{array}{l}\text { Modeling the clinical encounter to predict patient satisfaction, clinician satisfaction, and patient outcomes. } \\
\text { Use length of consult time as one of the predictors (examples of others: types of information shared, type of } \\
\text { clinician, diagnosis). }\end{array}$ \\
\hline & $\begin{array}{c}\text { In what stages of the cancer continuum does the length of consultation impact patient satisfaction, clinician } \\
\text { satisfaction, and patient outcomes? }\end{array}$ \\
\hline & What is the cost effectiveness of longer consultation times? \\
\hline \multirow[t]{5}{*}{ Routine assessment interventions } & $\begin{array}{l}\text { Conduct a high-quality systematic review examining the impact of routine standard assessment (across cancer } \\
\text { care continuum) on delivery of cancer care, satisfaction (patient and clinician), and clinical outcomes }\end{array}$ \\
\hline & What is the impact of routine standard assessment on other aspects of cancer care other than pain? \\
\hline & $\begin{array}{l}\text { Conduct a well-designed randomized trial to evaluate the impact of routine standard assessments on delivery } \\
\text { of care (fidelity), satisfaction of care (patient and clinician), and clinical outcomes }\end{array}$ \\
\hline & $\begin{array}{l}\text { Compare and contrast methods used to determine and create tools to support implementation of routine } \\
\text { standard assessments to ensure they are based on evidence and acceptable to clinicians and patients }\end{array}$ \\
\hline & $\begin{array}{c}\text { Research examining how to implement routine standard assessments into an oncology practice setting } \\
\text { (ambulatory or in-patient) so that it is acceptable (to management, clinicians, patients), effective, and cost } \\
\text { effective }\end{array}$ \\
\hline
\end{tabular}

Chronic care model (CMM) interventions

Conduct a high-quality systematic review examining the impact of CMM on delivery of cancer control, satisfaction (patient, clinician, policy), and clinical outcomes

Research (qualitative and/or scoping review) to assess whether CCM applies well to the cancer control context. Which components of the CCM (if any) are most relevant to cancer control? Which aspect of cancer control (e.g., diagnosis) lends itself to the CCM model?

Design, evaluate, and refine tools to support each of the six CCM components using high-quality methods

Models of care/integrated care interventions 1

Research to better understand for what cancer diagnoses, cancer care options, stages in the continuum, and contexts (e.g., geography) are different models of care and integration of services most appropriate (e.g., systematic review, case study intervention)

High-quality economic analysis comparing different models of care

Research aimed to analyze (and perhaps statistically model) existing models of care to better understand the mechanisms underlying the processes and the outcomes of different approaches

Deconstruction of existing systematic reviews to better understand the mechanisms underlying different models of care

Develop methods to better measure the concepts of shared care and integrated care

Models of care/integrated care interventions 2
Development/identification, implementation, and evaluation (process, satisfaction, patient outcomes) of various models (care and service) aimed at the diagnostic stage of continuum and transition to treatment (e. g., systemic review, scoping review, or randomized trial)

As above but focused on treatment only (e.g., systematic review or scoping review)

As above but aimed at the treatment stage of the continuum and transition to survivorship or palliative care

How to best introduce new models of care or new clinical roles into the care system

Research aimed to test effectiveness, safety, satisfaction (patient, providers, and system) and cost effectiveness of new clinical roles in cancer control by non-medical clinical professionals

Shared-care implementation tactic Using high-quality randomized methods, compare and contrast different existing tactics aimed to facilitate interventions

communication between healthcare providers

Develop, test, and refine new tactics aimed at facilitating communication between different practitioners

Health information technology $(\mathrm{HIT})$ interventions
What are the most effective and efficient strategies to implement an HIT solution?

For what cancer-control contexts (e.g., continuum of care, diagnosis, practice setting) is an HIT solution most appropriate?

Does embedding evidence-based recommendations into the HIT solutions improve quality of care over HIT solutions alone? 
which we understand KT interventions. The application of these techniques is warranted. While this has been undertaken in some of the systematic reviews, it is not consistent, nor is it being done in the primary studies underpinning the existing reviews.

Thus, common principles of good scholarship and methodological rigor are required in systematic reviews of KT research and in the primary studies that underpin them. Namely, well-defined research questions, appropriate research design, patient-centered outcomes, analytic strategies to better understand the mechanisms associated with change, and completeness of reporting are necessary.

There are, however, limitations to our study. First, to manage scope and resource constraints of the project, we considered only systematic reviews available in databases of systematic reviews. While trying to avoid duplication, we acknowledge there may be other reviews that would have met our inclusion criteria that were not included in any of the three databases. Further, one review by Grimshaw (2006) [19] was found to be eligible during our search but was erroneously deleted and not included in our review. In addition, we acknowledge that there are likely primary studies not yet included in any of the systematic reviews we considered that would have been relevant to our question.

Second, this study was Canadian in focus with respect to members of the research team. While this conformed to the request for proposals criteria of the project's funders, it may be that a different composition of individuals would have yielded different conclusions. To advance the field, gathering a more international perspective may be warranted.

In summary, this project provides an overview of the evidence related to KT in cancer control. Given the current state of the evidence and the need for additional research in so many areas, we were not able to offer a definitive blueprint outlining a small manageable set of research priorities in this context. The field is open and considerable work is required. To ensure world-class research and research that will have a positive impact on people with cancer and on cancer system performance requires clarity and transparency of research scope and goals coupled with high expectations for the research community to achieve excellence in study design, execution, and reporting.

\section{Endnotes}

${ }^{a}$ Interventions to influence uptake of cancer screening were explored in a separate project and were not considered here [17]. Cancer prevention was out of scope for this project and the aforementioned project.

${ }^{\mathrm{b}}$ One eligible systematic review by Grimshaw et al. (2006) was inadvertently deleted from the systematic review sample [19]. It focused on guidance dissemination and implementation strategies. They found absolute improvement in performance of $14.1 \%$ for reminders, $8.1 \%$ for dissemination, $7.0 \%$ for audit and feedback, and $6 \%$ for multifaceted interventions. This review is not included in the summary statistics presented.

\section{Additional material}

Additional file 1: Research Team. List of the Research Team members and their affiliations

Additional file 2: Eligible Systematic Reviews. List of full citations of systematic reviews and the corresponding intervention cluster(s) [23-56]

Additional file 3: Interventions aimed at consumers. Table of data on each intervention aimed at consumers

Additional file 4: Interventions aimed at professionals. Table of data on each intervention aimed at professionals

Additional file 5: Interventions aimed at organizations. Table of data on each intervention aimed at organizations

\section{Acknowledgements}

The authors of this manuscript wish to acknowledge the research team of the project, the KT for Cancer Control Evidence Expert Panel Members, for their guidance and invaluable contributions. The Evidence Expert Panel Members include Dr. George Browman, Dr. Denise Bryant-Lukosius, Dr. Maureen Dobbins, Dr. Anna Gagliardi, Dr. Ian Graham, Dr. Jeremy Grimshaw, Dr. Mark Levine, Dr. Holger Shünemann, Dr. Hsien Seow, Dr. Marko Simunovic, Dr. Sharon Straus, and Dr. Jonathan Sussman.

The authors also wish to acknowledge Lisa Durocher for her assistance with data collection and auditing.

This review of reviews project was part of the overall "Knowledge Translation for Cancer Control in Canada" research study, conducted with the support of the Ontario Institute for Cancer Research (OICR) through funding provided by the Government of Ontario. The Canadian Partnership Against Cancer (CPAC) also supported the project through funding provided by the Government of Canada.

\section{Author details}

${ }^{1}$ McMaster University, Department of Oncology, Hamilton, Ontario, Canada. ${ }^{2}$ McMaster University, Department of Clinical Epidemiology, Hamilton, Ontario, Canada. ${ }^{3}$ McMaster University, School of Rehabilitation Science, Hamilton, Ontario, Canada.

\section{Authors' contributions}

MCB conceived of the study and participated in its design and execution. $J M$ participated in the study's design and coordination. MCB, JM, and KG were directly involved in the preparation of this manuscript. KG and LD were responsible for data collection and data synthesis. All authors read and approved the final manuscript.

\section{Competing interests}

The authors declare that they have no competing interests.

Received: 15 April 2011 Accepted: 20 December 2011 Published: 20 December 2011

\section{References}

1. Mandel JS, Bond JH, Church TR, Snover DC, Bradley GM, Schuman LM, Ederer F: Reducing mortality from colorectal cancer by screening for fecal occult blood. N Engl J Med 1993, 328:1365-1371.

2. Hardcastle JD, Chamberlain JO, Robinson MH, Moss SM, Amar SS, Balfour TW, James PD, Mangham CM: Randomised controlled trial of faecal-occult-blood screening for colorectal cancer. Lancet 1996, 348:1472-1477. 
3. Kronborg O, Fenger C, Olsen J, Jørgensen OD, Søndergaard O: Randomised study of screening for colorectal cancer with faecal-occult-blood test. Lancet 1996, 348:1467-1471.

4. Mandel JS, Church TR, Bond JH, Ederer F, Geisser MS, Mongin SJ, Snover DC, Schuman LM: The effect of fecal occult-blood screening on the incidence of colorectal cancer. N Engl J Med 2000, 343:1603-1607.

5. Verma S, Trudeau M, Pritchard K, Oliver T, members of the Breast Cancer Disease Site Group: The role of the taxanes in the management of metastatic breast cancer.[http://www.cancercare.on.ca/common/pages/ UserFile.aspx?fileld=34140], Practice Guideline Report \# 1-3 Version 2.2003.

6. Trudeau M, Eisen A, Messersmith H, Pritchard Kl, and the Breast Cancer Disease Site Group: Adjuvant taxane therapy for women with early-stage, invasive breast cancer: A Clinical Practice Guideline. 2006 [http://www. cancercare.on.ca/common/pages/UserFile.aspx?fileld=34128], Evidencebased Series \#1-7.

7. Trudeau M, Sinclair S, Clemons M, Shelley W, members of the Breast Cancer Disease Site Group: The role of taxanes in neoadjuvant chemotherapy for women with non-metastatic breast cancer. 2004 [http://www.cancercare.on. ca/common/pages/UserFile.aspx?fileld=13886], Practice Guideline Report \#1-20,

8. Crump M, Trudeau M, Sinclair S, O'Malley F, members of the Breast Cancer Disease Site Group: The role of trastuzumab (Herceptin ${ }^{\circledR}$ ) in the treatment of women with HER2/neu-overexpressing metastatic breast cancer.[http://www.cancercare.on.ca/common/pages/UserFile.aspx? fileld=13870], Practice Guideline Report \#1-15 (Version 2.2004).

9. Hanks G, Cherny N, Fallon M: Opioid analgesic therapy. In Oxford Textbook of Palliative Medicine.. 3 edition. Edited by: Doyle D, Hanks G, Cherny N and Calman K. New York: Oxford University Press; 2005:318.

10. Francke AL, Smit MC, de Veer AJE, Mistiaen P: Factors influencing the implementation of clinical guidelines for health care professionals: a systematic meta-review. BMC Med Inform Decis Mak 2008, 8:38.

11. Cancer Quality Council of Ontario: Cancer Quality Index of Ontario 2009. 2010 [http://csqi.cancercare.on.ca/cms/One.aspx? portalld=40955\&pageld $=41027]$

12. Graham ID, Logan J, Harrison MB, Straus SE, Tetroe J, Caswell W, Robinson N: Lost in knowledge translation: Time for a map? J Contin Educ Health Prof 2006, 26:13-24

13. Dobrow MJ, Goel V, Lemieux-Charles L, Black NA: The impact of context on evidence utilization: a framework for expert groups developing health policy recommendations. Soc Sci Med 2006, 63:1811-1824.

14. Kitson A, Rycroft-Malone J, Harvey G, McCormack B, Seers K, Titchen A: Evaluating the successful implementation of evidence into practice using the PARIHS framework: theoretical and practical challenges. Implement Sci 2008, 3:1.

15. Ward V, House A, Hamer S: Developing a framework for transferring knowledge into action: a thematic analysis of the literature. $J$ Health Serv Res Policy 2009, 14:156-164.

16. Shojania KG, Sampson M, Ansari MB, Ji J, Doucette S, Moher D: How quickly do systematic reviews go out of date? A survival analysis. Ann Intern Med 2007, 21:224-233.

17. Brouwers M, De Vito C, Carol A, Carroll J, Cotterchio M, Dobbin M, Lent B, Levitt C, Lewis N, McGregor SE, Paszat L, Rand C, Wathen N: Interventions to increase the uptake of cancer screening: guideline recommendations. 2009 [http://www.cancercare.on.ca/common/pages/UserFile.aspx? fileld $=43168]$, Special Report EBS 15-7.

18. Shea BJ, Grimshaw JM, Wells GA, Boers M, Andersson N, Hamel C, Porter AC, Tugwell P, Moher D, Bouter LM: Development of AMSTAR: a measurement tool to assess the methodological quality of systematic reviews. BMC Med Res Methodol 2007, 7:10.

19. Grimshaw J, Eccles M, Thomas R, MacLennan G, Ramsay C, Fraser C, Vale L: Toward evidence-based quality improvement. Evidence (and its limitations) of the effectiveness of guideline dissemination and implementation strategies 1966-1998. J Gen Intern Med 2006, 21:S14-20.

20. Michie S: Designing and implementing behavior change interventions to improve population health. J Health Serv Res Policy 2008, 13:64-69.

21. Abraham C, Michie S: A taxonomy of behavior change techniques used in interventions. Health Psychol 2008, 27:379-387.

22. Cochrane Effective Practice and Organisation of Care Group (EPOC) (2011): The data collection checklist. 2011 [http://www.epoc.cochrane.org/].

23. Ammenwerth $E$, Schnell-Inderst $P$, Machan $C$, Siebert U: The effect of electronic prescribing on medication errors and adverse drug events: A systematic review. J Am Med Inform Assoc 2008, 15:585-600.
24. Baker R, Camosso-Stefinovic J, Gillies C, Shaw EJ, Cheater F, Flottorp S, Robertson N: Tailored interventions to overcome identified barriers to change: Effects on professional practice and health care outcomes. Cochrane Database Syst Rev 2010, 3:CD005470.

25. Beach MC, Gary TL, Price EG, Robinson K, Gozu A, Palacio A, Smarth C, Jenckes M, Feuerstein C, Bass EB, Powe NR, Cooper LA: Improving health care quality for racial/ethnic minorities: A systematic review of the best evidence regarding provider and organization interventions. BMC Public Health 2006, 6:104

26. Bennett MI, Bagnall AM, José Closs S: How effective are patient-based educational interventions in the management of cancer pain? Systematic review and meta-analysis. Pain 2009, 143:192-199.

27. Bosch-Capblanch X, Abba K, Prictor M, Garner P: Contracts between patients and healthcare practitioners for improving patients' adherence to treatment, prevention and health promotion activities. Cochrane Database Syst Rev 2007, 18:CD004808.

28. Chaudhry B, Wang J, Wu S, Maglione M, Mojica W, Roth E, Morton SC, Shekelle PG: Systematic review: impact of health information technology on quality, efficiency, and costs of medical care. Ann Intern Med 2006, 144:742-752.

29. Coleman K, Austin BT, Brach C, Wagner EH: Evidence on the chronic care model in the new millennium. Health Aff (Millwood) 2009, 28:75-85.

30. Conn VS, Hafdahl AR, Brown SA, Brown LM: Meta-analysis of patient education interventions to increase physical activity among chronically ill adults. Patient Educ Couns 2008, 70:157-172.

31. Doumit G, Gattellari M, Grimshaw J, O'Brien MA: Local opinion leaders: Effects on professional practice and health care outcomes. Cochrane Database Syst Rev 2007, 1:CD000125.

32. Edwards A, Gray J, Clarke A, Dundon J, Elwyn G, Gaff C, Hood K, Iredale R, Sivell $\mathrm{S}$, Shaw $\mathrm{C}$, Thornton $\mathrm{H}$ : Interventions to improve risk communication in clinical genetics: systematic review. Patient Educ Couns 2008, 71:4-25.

33. Evans R, Edwards A, Brett J, Bradburn M, Watson E, Austoker J, Elwyn G: Reduction in uptake of PSA tests following decision aids: systematic review of current aids and their evaluations. Patient Educ Couns 2005, 58:13-26.

34. Garg AX, Adhikari NK, McDonald H, Rosas-Arellano MP, Devereaux PJ, Beyene J, Sam J, Haynes RB: Effects of computerized clinical decision support systems on practitioner performance and patient outcomes: a systematic review. JAMA 2005, 293:1223-1238.

35. Gaston CM, Mitchell G: Information giving and decision-making in patients with advanced cancer: a systematic review. Soc Sci Med 2005, 61:2252-2264.

36. Goldberg GR, Morrison RS: Pain management in hospitalized cancer patients: a systematic review. J Clin Oncol 2007, 25:1792-1801.

37. Gysels M, Richardson A, Higginson IJ: Does the patient-held record improve continuity and related outcomes in cancer care: a systematic review. Health Expect 2007, 10:75-91.

38. Haynes RB, Ackloo E, Sahota N, McDonald HP, Yao X: Interventions for enhancing medication adherence. Cochrane Database Syst Rev 2008, 2 CD000011.

39. Heneghan CJ, Glasziou P, Perera R: Reminder packaging for improving adherence to self-administered long-term medications. Cochrane Database Syst Rev 2006, 1:CD005025.

40. Jamtvedt G, Young JM, Kristoffersen DT, O'Brien MA, Oxman AD: Audit and feedback: effects on professional practice and health care outcomes. Cochrane Database Syst Rev 2006, 2:CD000259.

41. Joosten EA, DeFuentes-Merillas L, de Weert GH, Sensky T, van der Staak CP, de Jong CA: Systematic review of the effects of shared decision-making on patient satisfaction, treatment adherence and health status. Psychother Psychosom 2008, 77:219-226.

42. Lewis RA, Neal RD, Williams NH, France B, Hendry M, Russell D, Hughes DA, Russell I, Stuart NS, Weller D, Wilkinson C: Follow-up of cancer in primary care versus secondary care: systematic review. Br J Gen Pract 2009, 59: e234-47.

43. Murray E, Burns J, See TS, Lai R, Nazareth I: Interactive health communication applications for people with chronic disease. Cochrane Database Syst Rev 2005, 4:CD004274.

44. O'Brien MA, Rogers S, Jamtvedt G, Oxman AD, Odgaard-Jensen J, Kristoffersen DT, Forsetlund L, Bainbridge D, Freemantle N, Davis DA, Haynes RB, Harvey EL: Educational outreach visits: effects on professional 
practice and health care outcomes. Cochrane Database Syst Rev 2007, 4: CD000409.

45. Raynor DK, Blenkinsopp A, Knapp P, Grime J, Nicolson DJ, Pollock K, Dorer G, Gilbody S, Dickinson D, Maule AJ, Spoor P: A systematic review of quantitative and qualitative research on the role and effectiveness of written information available to patients about individual medicines. Health Technol Assess 2007, 11:iii, 1-160..

46. Rotter T, Kinsman L, James E, Machotta A, Willis J, Snow P, Kugler J: Clinical pathways: Effects on professional practice, patient outcomes, length of stay and hospital costs. Cochrane Database Syst Rev 2010, 3:CD006632.

47. Santo A, Laizner AM, Shohet $L$ : Exploring the value of audiotapes for health literacy: a systematic review. Patient Educ Couns 2005, 58:235-243.

48. Scheuner MT, Sieverding P, Shekelle PG: Delivery of genomic medicine for common chronic adult diseases: a systematic review. JAMA 2008, 299:1320-1334.

49. Shepperd S, McClaran J, Phillips CO, Lannin NA, Clemson LM, McCluskey A, Cameron ID, Barras SL: Discharge planning from hospital to home. Cochrane Database Syst Rev 2010, 1:CD000313.

50. Shojania KG, Jennings A, Mayhew A, Ramsay CR, Eccles MP, Grimshaw J: The effects of on-screen, point of care computer reminders on processes and outcomes of care. Cochrane Database Syst Rev 2009, 3: CD001096.

51. Smith SM, Allwright $\mathrm{S}, \mathrm{O}^{\prime}$ Dowd T: Effectiveness of shared care across the interface between primary and specialty care in chronic disease management. Cochrane Database Syst Rev 2007, 3:CD004910.

52. Smith SM, Allwright S, O'Dowd T: Does sharing care across the primaryspecialty interface improve outcomes in chronic disease? a systematic review. Am J Manag Care 2008, 14:213-224.

53. Thomas L, Cullum N, McColl E, Rousseau N, Soutter J, Steen N: Guidelines in professions allied to medicine. Cochrane Database Syst Rev 2000, 2: CD000349.

54. Waljee JF, Rogers MA, Alderman AK: Decision aids and breast cancer: Do they influence choice for surgery and knowledge of treatment options? J Clin Oncol 2007, 25:1067-73.

55. Wilson AD, Childs S: Effects of interventions aimed at changing the length of primary care physicians' consultation. Cochrane Database Syst Rev 2006, 1:CD003540.

56. Wofford JL, Smith ED, Miller DP: The multimedia computer for officebased patient education: a systematic review. Patient Educ Couns 2005, 2:148-57.

doi:10.1186/1748-5908-6-130

Cite this article as: Brouwers et al:: The landscape of knowledge translation interventions in cancer control: What do we know and where to next? A review of systematic reviews. Implementation Science 2011 6:130.

\section{Submit your next manuscript to BioMed Central and take full advantage of:}

- Convenient online submission

- Thorough peer review

- No space constraints or color figure charges

- Immediate publication on acceptance

- Inclusion in PubMed, CAS, Scopus and Google Scholar

- Research which is freely available for redistribution 